\title{
A concepção do indicador analfabetismo nas mudanças censitárias no Brasil
}

\section{The design of the indicator illiteracy in the census change in Brazil}

\author{
Ada Augusta Celestino Bezerra ${ }^{1}$ \\ Dinamara Garcia Feldens ${ }^{2}$ \\ Márcia Alves de Carvalho Machado ${ }^{3}$ \\ Universidade Tiradentes, UNIT (Brasil)
}

Recibido: $21-11-14$
Aprobado: $18-12-14$

\begin{abstract}
${ }^{1}$ (adaaugustaeduc@gmail.com). Pós-doutoramento em Educação pelo Instituto de Educação da Universidade de Lisboa. Doutora em Educação pela Universidade de São Paulo. Mestra em Educação pelo Instituto de Estudos Avançados em Educação da Fundação Getúlio Vargas - RJ. Pedagoga. Professora do Doutorado e do Mestrado em Educação do PPED/ UNIT e do Curso de Pedagogia da UNIT. Líder do Grupo de Pesquisa em Políticas Públicas, Gestão Socioeducacional e Formação de Professores (GPGFOP/UNIT/ CNPq). Coordenadora do Observatório de Educação da UNIT/CAPES. Algumas publicações: BEZERRA, A. A. C.; NASCIMENTO, M. B. da C. (Orgs.). (2013). Educação e formação de professores: questões contemporâneas. Fortaleza: UFC. BEZERRA, A. A. C.; SILVA, S. M. S. M. T. (2014). Desenvolvimento rural e educação básica: objeto pedagógico na formação docente. In: ALMEIDA, A. R. S. (Org.). Educação e formação. Diferentes contextos. Salvador: EDUFBA. BEZERRA, A, A. C. et al. (2015). Profissão professor: entre Prometeu, Ulisses, Édipo e a Síndrome de Burnout. Fortaleza: UFC.

2 (dfeldens@hotmail.com). Pós-doutoramento em Filosofia da Educação pela Universidade Complutense de Madri - UCM. Pesquisadora do Instituto Tecnológico de Pesquisa ITP e professora PPG I da Universidade Tiradentes no Programa de Pós Graduação em Educação na UNIT. Membro do Comitê Científico da Universidade Tiradentes. Coordenadora Local do Doutorado Interinstitucional/ DINTER em Educação em parceria da UNIT com o PED da PUC/RS. Líder do Grupo de Pesquisa Educação, Cultura e Subjetividade. Algumas publicações: FELDENS, D. G. (Org.). (2013). Arte e filosofia na mediação de experiências formativas contemporâneas. Fortaleza: EdUECE. OLIVEIRA, R. M. C.; FELDENS, D. (2014). A cidaderede como currículo informal: o facebbok, a comunicação ubíqua e as manifestações de rua no Brasil 2013. In: PORTO, C.; SANTOS, E. (Orgs). (2014). Facebook e a educação: publicar, curtir e compartilhar. Campina Grande: EDUEPB. FELDENS, D. G. et al. (2015). Escritos outros, poemas intermináveis: vida, pesquisa e educação. Educação por Escrito, v. 6, p. 26-38.

3 (mac_machado@hotmail.com). Mestra em Educação pela Universidade Tiradentes. Integrante do Programa Observatório da Educação da CAPES - Projeto TRANSEJA2, vinculado à Universidade Tiradentes. Professora da Educação Superior na Faculdade Sergipana (FASER). Pesquisadora do Grupo de Pesquisa em Políticas Públicas, Gestão Socioeducacional e Formação de Professores (GPGFOP/UNIT/CNPq). Algumas publicações: MACHADO, M. A. de C. et al. (2013). Transdisciplinaridade na educação de jovens e adultos: uma experiência de ensino/pesquisa/extensão. In: ALMEIDA, M. J. de M. et al. (Orgs.). (2013). Práticas pedagógicas na educação de jovens e adultos: interdisciplinaridade, interculturalidade e intersetorialidade. Aracaju: Infographics. MACHADO, M. A. de C. (2013). Alteridade intrínseca na teoria marxista: um estudo a partir da obra $\mathrm{O}$ capital. In: Anais $6^{\circ}$ Encontro de Formação de Professores. Aracaju. MACHADO, M. A. de C. et al. (2014). O cotidiano docente em uma sala de aula da EJA, a partir da observação em uma escola de Aracaju. In: Anais do VIII Simpósio Nacional de Educação/II Colóquio Internacional de Políticas Educacionais e Formação de Professores. Frederico Westphalen: URI RS.
\end{abstract}




\title{
Resumo
}

Este artigo tem o objetivo de caracterizar as mudanças de concepção ocorridas quanto ao indicador analfabetismo ao longo das pesquisas censitárias no Brasil, publicadas de 1920 até os dias atuais e suas implicações. Neste sentido, tratase de uma análise feita a partir do levantamento dos conceitos e características do quesito alfabetização nos censos, considerando as mudanças conceituais e metodológicas ocorridas durante a história. No delineamento do estudo utilizamos os procedimentos da pesquisa bibliográfica, de campo e documental. No decorrer da análise confirmou-se a hipótese de que o conceito de alfabetização nos levantamentos censitários do Brasil, embora tenha se alterado ao longo dos anos de 1950, 1980 e 2000, não incorporou a ampliação do seu significado no que diz respeito a sua evolução epistemológica e metodológica. Dessa forma, são informações subsidiam equivocadamente a formulação de políticas públicas nesta área, contribuindo para sua ineficácia e inefetividade quanto à superação do analfabetismo.

Palavras-chave: Alfabetização, Brasil, Censos, Indicador, Políticas Públicas.

\begin{abstract}
This article aims to characterize the design changes as illiteracy indicator along the census surveys in Brazil, published from 1920 to the present day and its implications. In this sense, it is an analysis from the survey of concepts and literacy requirement of the features in the census, considering the conceptual and methodological changes that have occurred throughout history. In the study design we used the procedures of bibliographic research, field and documental. During the analysis confirmed the hypothesis that the concept of literacy in censuses of Brazil, although it has changed over the years 1950, 1980 and 2000 did not incorporate the expansion of its significance with regard to its epistemological evolution and methodological. Thereby, this information mistakenly subsidize the formulation of public policies in this area, preventing them to be the most suitable for overcoming illiteracy.
\end{abstract}

Key-words: Literacy, Brazil, Census, Indicator, Public Policy. 


\section{Introdução}

Os primeiros preceitos sobre a educação no Brasil tornaram-se mais evidentes após o processo de independência, quando foi criada a primeira constituição para o país, em 1824. Era prevista pelo artigo 179 inciso 32, a instrução primária e gratuita para todos os cidadãos. Embora previstos na Constituição outorgada, os princípios educativos não foram observados, mas apenas cumpriam o papel de tornar público e reproduzir, ao menos no aspecto legal, os ideais liberais em moda na Europa e na América do Norte (Freire: 2001).

Somente em 1827, com a lei de 15 de outubro, foi organizada a educação nacional, com a criação das escolas de primeiras letras nas cidades, vilas e lugarejos do país. É a partir dessa lei de 1827 que, segundo Cury (2006: 48) "inicia-se um intenso debate entre os legisladores e homens letrados a respeito do papel que a escolarização deveria ter dali em diante".

Apesar da intenção dos legisladores em obter uma lei geral para a instrução pública, o ato adicional de 1834 transferiu para as províncias essa responsabilidade, o que representou obstáculo para a expansão da escolarização no país nas primeiras décadas do século XIX, uma vez que as mesmas não possuíam recursos suficientes para garantir uma "rede escolar" (Cury 2006). Para Freire (2001: 55) "as províncias, sem recursos humanos e econômicos, não puderam levar a bom termo, se é verdade que tal fato as interessava, nem quantitativamente nem qualitativamente, o ensino primário e o médio”.

Essa situação de precariedade financeira das províncias também foi reconhecida por Farias Filho (2000), o que as fragilizava e aos respectivos Presidentes e Assembleias Provinciais, em cujos relatórios apontavam qualquer realização nessa área como "um grande feito político-administrativo" (Faria Filho 2000: 139). Na sua perspectiva outros fatores caracterizavam o ensino nesse período: a presença do Estado era pequena e pulverizada como, algumas vezes, também considerada perniciosa no ramo da instrução; a escola para os pobres, mesmo em se tratando de brancos e livres, era específica para o aprendizado das primeiras letras; a instrução possibilitaria arregimentar o povo para um projeto de país independente, criando também as condições para uma participação controlada na definição dos destinos do país.

No final do século XIX, a taxa nacional de analfabetos, apurada pela primeira vez em 1872, quando do primeiro recenseamento geral no Brasil, era de $82,3 \%$ da população, o que representava em números absolutos aproximadamente 7.200.000 de pessoas (Ferraro 2009). Dessa população, a grande maioria era formada pela soma de negros e pardos, escravos livres e os libertos, embora se deva considerar que os primeiros só puderam frequentar as 
escolas após 1879 com a Reforma do Ensino de Leôncio de Carvalho (Ferraro 2009).

Ainda que ocorressem debates e intenções quanto à escolarização, a questão do analfabetismo era pouco considerada, como esclarece Paiva (1990: 9) "ao longo de grande parte da nossa história essa questão não esteve posta. Ela de fato emerge com a reforma eleitoral de 1882 (Lei Saraiva), que derruba a barreira da renda, mas estabelece a proibição do voto do analfabeto".

No final do século XIX estabelece-se a preocupação com o analfabetismo por conta da posição incômoda ocupada mundialmente pelo Brasil ao ser constatada uma taxa de $83,62 \%$ de analfabetos no país, excluídos os menores de 5 anos, sendo a pior posição mundial (Paiva 1990: 10). Ferraro $(2002 ; 2009)$ afirma que este é um período de estabilidade da taxa nacional de analfabetismo em nível extremamente elevado, situada entre $82 \%$ e $83 \%$ para as pessoas de 5 anos ou mais, sendo que esta situação perdurou até o início da República. Nessa concepção o analfabetismo emergiu no Brasil como uma questão política e econômica, pois as constituições nacionais perpetuaram até a Carta Magna de 1988 o caráter discriminatório, rotulador e excludente em relação ao analfabeto.

É neste quadro de emergência de uma solução para o problema do analfabetismo que as pesquisas censitárias vão incorporando e, ao mesmo tempo, sendo moldadas para atender ao nível de informações requeridas e que possibilitem, igualmente, melhorar a imagem do país no contexto internacional através das estatísticas.

As características sobre instrução estiveram sempre presentes desde o primeiro censo do país e se o problema do analfabetismo não esteve posto e apenas emergiu ao final do século XIX, é ainda mais lamentável constatar que na atualidade a superação do analfabetismo ainda se configura como um desafio para a educação brasileira.

Este estudo tem o objetivo de configurar as mudanças que se deram no conceito de alfabetização no transcorrer das pesquisas censitárias no Brasil, publicadas de 1920 até os dias atuais. Neste sentido, será analisado pelo levantamento dos conceitos e características deste quesito se as alterações ocorridas acompanharam as mudanças conceituais e metodológicas ocorridas na história da alfabetização ou literacia no Brasil e no mundo. É importante ressaltar que a análise aqui proposta recaiu sobre o problema do analfabetismo de jovens e adultos, grupo que nas pesquisas censitárias demográficas corresponde àquelas pessoas de 15 anos ou mais de idade.

A hipótese sugere que o entendimento de alfabetização nos levantamentos censitários no Brasil não tem acompanhado as mudanças conceituais e metodológicas relativas a este processo, o que mascara a real situação do problema do analfabetismo de jovens e adultos no país, na medida em que essas informações subsidiam a formulação de políticas públicas inadequadas, porque 
fundadas em bases inconsistentes, sobre as quais pesa a realidade de cada local, com suas especificidades sociais, culturais, políticas e econômicas. Vale salientar que é pressuposto desta pesquisa a convicção, hoje já consenso internacional, de que um dos fatores que contribui decisivamente para o desenvolvimento social e econômico de um país é a qualidade da sua Educação Básica, e que esta, se realizada eficaz e efetivamente, inviabilizará o analfabetismo de jovens e adultos. Bezerra e Chaves (2013) discutem essa relação na perspectiva da educação nacional e internacional.

\section{Mudanças censitárias e a construção do conceito de alfabetização}

O Brasil utiliza diversos tipos de pesquisas estatísticas que servem de fonte para conhecer as suas características econômicas, demográficas e sociais, entre outras. Nesta investigação optou-se por analisar os dados estatísticos sobre alfabetização publicados pelas pesquisas censitárias demográficas, por considerar que estes produzem informações estatísticas da população e permitem descrever seu estado no momento do levantamento e sua estrutura segundo determinadas características, sendo importante, neste estudo, aquelas relativas à instrução ou ao ensino e mais especificamente sobre alfabetização.

$\mathrm{Na}$ linguagem demográfica, pode-se dizer que os levantamentos censitários e amostrais do IBGE, entre outros, retratam o estado educacional da população, por meio de dados sobre características como alfabetização, frequência ou não à escola e grau e série frequentados, anos de estudo e grau concluído (Ferraro 2002: 25).

O IBGE também realiza a Pesquisa Nacional por Amostra de Domicílios - PNAD desde 1967 a qual em 1981 estendeu-se a todo o país, com exceção da área rural da antiga Região Norte, compreendida pelas unidades da federação: Rondônia, Acre, Amazonas, Roraima, Pará e Amapá (IBGE 2001). Em 2004 os resultados passaram a ser apresentados distinguindo as áreas urbana e rural de todas as Unidades da Federação, as Grandes Regiões e o total do Brasil (IBGE 2011).

Considera-se como ponto de partida para a análise das mudanças censitárias aqui desenvolvidas, o censo de 1920, uma vez que se aceita a advertência de Ferraro (2009) com relação à inconsistência dos dados sobre o movimento da taxa de analfabetismo entre 1890 a 1920, que chegou a apresentar uma queda abrupta em torno de $13 \%$ sendo que nos 20 anos seguintes manteve-se quase inalterada, o que não condizia com a realidade. Cabe ainda ressaltar a lacuna representada pelo fato de que em 1910 e 1930 não foram realizadas operações censitárias no país. 
Em 1920, conforme regulava o artigo $3^{\circ}$ do Decreto $\mathrm{n}^{\circ} 14.026$, de 21 de janeiro do mesmo ano, o recenseamento geral da população foi realizado através de lista de famílias, sendo a pesquisa:

Conforme natureza do domicilio, particular ou collectivo, inquirindo-se de cada habitante o nome, sexo, a idade, o estado civil, a nacionalidade, a profissão, o gráo de instrucção, a residencia e os defeitos physicos, sómente quanto á cegueira e á surdo-mudez. Além destes quesitos, serão formulados mais dous referentes á condição ou situação do individuo que habita o domicilio e ao numero de pessôas que tem a seu cargo. (IBGE 2013: 8).

As informações relativas à instrução foram coletadas por listas domiciliares, sendo dois modelos: "Lista para domicílio particular" - Modelo n 1 e "Lista para domicílio collectivo" - Modelo $\mathrm{n}^{\circ} 2$, indicado o tipo de instrução da população através da pergunta: Sabe ler e escrever? (Item 7 no Modelo $n^{\circ} 1 \mathrm{e}$ item 10 no Modelo $n^{\circ} 2$ ). Essas listas eram distribuídas aos moradores através de visitas pelos agentes recenseadores que, posteriormente, as coletavam, num prazo fixado, e as encaminhavam juntamente com outros documentos para apuração. Na impossibilidade de um morador preencher a lista, o próprio agente deveria empregar todos os meios ao seu alcance para corrigir ou completar a informação, sendo considerado delito punível com multa qualquer inexatidão.

$\mathrm{Na}$ terceira parte do documento "Apuração do Recenseamento de 1920: Instrucções Especiaes para Apuração dos Censos Demographico e Economico", no item 48 - Instrucção, página 73 dos Annexos, Volume I do censo de 1920, constata-se a orientação que na falta de declaração do recenseado a pergunta sobre a instrução, deveria ser levado em conta a idade e a profissão do respondente e, na impossibilidade de obter esses esclarecimentos, deveriam ser registrados entre os que não sabem ler e escrever. Esta orientação denota o uso de subjetividade na apuração dos dados relativos à instrução, o que certamente interferia nos resultados estatísticos, uma vez que o próprio agente recenseador, por não ter este quesito respondido, poderia determinar se o morador era ou não alfabetizado. De acordo com o item $5^{\circ}$ - Grao de Instrucção, da Quarta Parte do documento, que trata das orientações de separação das cartolinas quando da apuração, os grupos de idade utilizados para coleta de informações sobre instrução foram: 0 a 6 anos, 7 a 14 anos, 15 a 20 anos e 21 e mais anos de idade. Este censo apontou aproximadamente 18,5 milhões de pessoas analfabetas no país.

Em 1934 foi criado pelo Decreto $\mathrm{n}^{0} 24.609$ o Instituto Nacional de Estatística que possuía autonomia para realizar a coordenação das atividades estatísticas da União, das Unidades da Federação e dos Municípios. Em julho de 1936 foi convocada a Convenção Nacional de Estatística que se realizou no mês seguinte; nela fixaram-se as bases para a constituição e regulamentação do 
Conselho Nacional de Estatística, órgão principal do Instituto com semelhantes funções e, em menos de um ano, incorporou-se a este sistema o Conselho Brasileiro de Geografia, criado pelo Decreto no 1.527 de 1937, que reunia e coordenava com a colaboração do Ministério da Educação e Saúde, estudos sobre a geografia do Brasil. No ano seguinte, o Conselho Brasileiro de Geografia passou a chamar-se Conselho Nacional de Geografia e pelo Decreto $n^{\circ} 218$ o sistema nacional de serviços estatístico-geográficos passou a denominar-se Instituto Brasileiro de Geografia e Estatística. No mesmo ano, pelo Decreto $\mathrm{n}^{\mathrm{o}}$ 237, ainda é criada a Comissão Censitária Nacional, responsável pela direção superior do Serviço Nacional de Recenseamento. Também em 1938 pelo Decreto $n^{\circ} 969$, foram estabelecidas as normas que definem a periodicidade decenal para as pesquisas censitárias do país.

A partir de 1940 verifica-se que ao longo das pesquisas censitárias no país os parâmetros para investigação sobre educação, nesta inserida a alfabetização, foram sofrendo mudanças. Para Oliveira e Simões (2005) nessa década começa uma nova etapa da história das estatísticas populacionais no Brasil, sobretudo quanto à dinâmica demográfica, graças ao esforço e conhecimento do demógrafo italiano Giorgio Mortara (1885-1967) e criam-se condições para estudos demográficos abrangendo o conjunto do país. Muitos foram os dispositivos criados para propiciar essas condições.

O censo demográfico de 1940, conforme consta em nota prévia do volume II da publicação relativa aos resultados, preocupou-se além da instrução também com a questão da cultura brasileira, de forma específica com a língua e a religião. A questão da língua foi pesquisada até o censo de 1950 e referiase à condição da população falar ou não corretamente o Português, e de como era usada habitualmente esta ou outra língua. Ainda era associada a este item a classificação da nacionalidade, se estrangeiro ou não. Sobre a religião a pesquisa oportunizava identificar os credos das pessoas investigadas.

Quanto à instrução, o censo de 1940 ampliou para 7 quesitos na coleta de informações que verificava a situação e, em parte, as perspectivas sobre educação. Sob esse ponto de vista esse censo para a verificação pura e simples do analfabetismo, dividia a população em três parâmetros: os que sabiam ler e escrever, os que não sabiam e aqueles que não declaravam a instrução. Esta classificação estava vinculada a outros aspectos como sexo, cor, nacionalidade e grupo de idade. Percebe-se também no censo de 1940 uma interferência na forma de apuração dos resultados estatísticos sobre instrução, pois em ocorrendo abstenções às perguntas o sujeito seria considerado analfabeto, o que introduz vieses na investigação.

Verifica-se neste censo uma ampliação dos grupos de idade pesquisados quanto à instrução, em relação ao censo anterior. Enquanto no censo de 1920 os pesquisados eram divididos em 4 faixas etárias que variavam entre 0 a 20 anos 
e mais de idade, no censo de 1940 ampliou-se para 9 grupos de idade, sendo: 5 a 9 anos, 10 a 19 anos, 20 a 29 anos, 30 a 39 anos, 40 a 49 anos, 50 a 59 anos, 60 a 69 anos, 70 a 79 anos e 80 anos e mais de idade. Também é apresentado na pesquisa o número de pessoas de 10 ou mais de idade que interromperam os estudos no grau elementar (anos iniciais de estudos), por sexo, regiões fisiográficas e unidade da federação. O país possuía uma população de 34,79 milhões de pessoas acima dos 5 anos de idade, sendo que desta, cerca de $61 \%$ não sabiam ler e escrever. Entre as de 10 anos e mais, 31,78 milhões de pessoas, aproximadamente $24 \%$ haviam interrompido os estudos no grau elementar. A taxa de analfabetismo das pessoas de 15 anos ou mais de idade era de $56 \%$, o que indica a ineficácia da educação elementar ou anos iniciais de estudo com a consequente evasão de alunos desse nível de ensino.

Observa-se, a partir da pesquisa censitária de 1950, a sexta do Brasil, que o país já se articulava com os padrões internacionais. Na introdução desse censo apresentam-se informações sobre as convenções internacionais e afirma-se que o levantamento "orientou-se por estudos e recomendações das Organizações das Nações Unidas, integrando-se no Censo das Américas de 1950, promovido pelo Instituto Interamericano de Estatística - IASI, órgão assumido pela Organização dos Estados Americanos - OEA”. Neste aspecto as pesquisas atendiam,

[...] aos padrões internacionais da época, visando à uniformidade e comparabilidade dos resultados com outras nações, objetivos que de certo modo já estavam presentes nas preocupações dos responsáveis pelo planejamento do Censo de 1940, o Brasil participa, em 1946, do programa de censos simultâneos proposto pelo Comitê do Censo das Américas (Oliveira; Simões 2005: 293).

Através desse órgão, citado pelos autores, "as nações americanas concordaram em estabelecer as bases de um programa mínimo visando à uniformidade de conceitos e a comparabilidade dos resultados do Censo das Nações Americanas" (IBGE 1956: x). O Brasil desde sua participação a partir de meados do século XVIII em congressos internacionais passou a acatar as recomendações formuladas por entidades de âmbito internacional, a exemplo da Liga das Nações e Organização das Nações Unidas, no que diz respeito aos seus recenseamentos. Ressalta-se que desde o século XVIII, conforme Almeida (2001: 27), o Brasil buscava enquadramento, de forma emergente, no "multilateralismo econômico da época através da construção institucional de um instrumento diplomático adequado ao país". A partir das décadas seguintes estas relações internacionais vão se ampliando e consolidando no país, no âmbito das esferas federal, estadual e municipal, passando a influenciar diversos processos, não apenas econômicos, mas culturais, sociais e outros. 
Esse censo de 1950 reduziu os quesitos investigados quanto à instrução, excluindo dos boletins as indagações que visavam ao conhecimento do número de "pessoas que recebiam instrução, a espécie, o grau dessa instrução e o local onde era ministrada" (IBGE 1956: xiv). Na apresentação dos resultados não figurava o número de pessoas que interromperam os estudos nos anos iniciais de instrução. Quanto à alfabetização essa pesquisa passou a considerar pessoas alfabetizadas somente aquelas capazes de ler e escrever um bilhete simples, em um idioma qualquer; aquelas que assinassem apenas o próprio nome seriam consideradas analfabetas. O país apresentava um total de 24,9 milhões de pessoas de 5 anos e mais de idade que não sabiam ler e escrever. Quanto aos analfabetos percebe-se a inclusão de mais duas faixas etárias: de 15 a 19 anos e de 20 a 24 anos, reflexo da alteração para grupos quinquenais de 0 a 29 anos conforme informado na publicação Volume I do Censo Demográfico (IBGE 1956: xvii).

É importante mencionar que em 1950 a população de jovens e adultos, considerando as pessoas de 15 anos e mais, faixa inicial para a análise do analfabetismo no país e para efeito de comparações internacionais, em especial pela Unesco [embora na América Latina, conforme Ferraro (2002) tem sido utilizada a população de 10 anos ou mais], representava aproximadamente $70 \%$ da população brasileira, ou seja, cerca de 30 milhões de pessoas, das quais, aproximadamente $50,5 \%$ não sabiam ler e escrever, 5,5\% menos que a década anterior. Destas, apenas 1,4 milhão de pessoas eram idosas acima de 60 anos e mais, o que reflete a situação crítica da população em idade ativa do país quanto à educação, diante da ambição dos projetos de desenvolvimento e crescimento econômico que este mantinha. Conforme mencionado na publicação desse censo, ocorreu uma modificação na apuração quanto à instrução no que se refere aos grupos de idade pesquisados. A publicação esclarece que foram investigados: a instrução, o nível e o grau e espécie do curso completo de nível mais elevado dos pesquisados (IBGE 1956).

$\mathrm{Na}$ apresentação dos quadros o censo de 1950 tem a mesma divisão dos parâmetros do censo de 1940, agregando os dados sobre a situação de instrução das pessoas de 5 anos e mais, por sexo, situação de domicílio, cor e nacionalidade segundo grupos de idades, novamente modificados, sendo 11 grupos assim distribuídos: 5 a 9 anos, 10 a 14 anos, 15 a 19 anos, 20 a 24 anos, 25 a 29 anos, 30 a 39 anos, 40 a 49 anos, 50 a 59 anos, 60 a 69 anos, 70 a 79 anos e 80 anos e mais de idade.

Observa-se ainda no censo de 1950 que ocorrem mudanças no detalhamento dos dados investigados sobre instrução, pois esses passam a ser divulgados quanto ao domicílio dos pesquisados (urbano, suburbano ou rural) e conforme as regiões fisiográficas (Norte, Nordeste, Leste, Sul e Centro-Oeste) e unidades da federação. Desta forma são destacadas as pessoas de 5 anos e mais por 
sexo, situação de domicilio (urbano, suburbano e rural) e instrução, segundo as regiões fisiográficas e a unidade da federação, assim como as pessoas de 5 a 14 anos (em idade escolar) com a indicação das que sabem ler e escrever, segundo as regiões fisiográficas e as unidades da federação. Percebe-se um número elevado de pessoas analfabetas nos domicílios rurais comparados aos outros dois domicílios: 3 milhões de analfabetos nos domicílios urbanos; 2,2 milhões de pessoas nos suburbanos e 19,8 milhões nos rurais.

Os censos de 1960 e 1970 mantêm o mesmo entendimento do censo anterior quanto ao conceito de alfabetização e passam a relacionar os dados a partir de apenas duas unidades fisiográficas - urbana e rural. Em 1960, na sétima pesquisa censitária do país o IBGE altera alguns conceitos; elimina o termo Instrução e substitui por Alfabetização para pesquisa dos analfabetos; elimina a expressão Nível Educacional e inclui Frequência à Escola; ainda insere a pesquisa de anos de estudo (frequência a algum curso, segundo a classificação de 1 a 17 anos de estudos correspondentes aos níveis elementar, médio $1^{\circ}$ e $2^{\circ}$ ciclos e superior, obtida via Declaração da última série de aprovação).

Quanto à alfabetização, distinguiam-se aquelas pessoas que sabiam ler e escrever um bilhete simples em idioma qualquer - alfabetizadas, daquelas que assinassem apenas o próprio nome - analfabeto. Mantiveram-se as informações de identificação de grupos de idade e sexo, sendo pesquisados 10 grupos de idade e os grupos de domicílio passaram a ser apenas dois: urbano (cidades e vilas) e rural (fora dos limites das cidades e vilas).

O levantamento de 1960 apontou 27,5 milhões de pessoas de 5 anos e mais analfabetas, sendo 7,8 milhões de pessoas nos domicílios urbanos e 19,8 nos rurais. A taxa de analfabetismo das pessoas de 15 anos ou mais de idade era de $39,6 \%$. Já em 1970 o país possuía 30,71 milhões de pessoas na faixa de 5 anos ou mais analfabetas, das quais aproximadamente 11,15 milhões estavam na zona urbana e 19,56 milhões na zona rural. A taxa de analfabetismo das pessoas de 15 anos ou mais era de 33,6\%, ou seja, reduzira-se $16,9 \%$ em relação a 1950 e 6\% em relação a 1960.

Contudo, é nos censos posteriores, de 1980 e 1991, que mudanças significativas são percebidas quanto à pesquisa sobre alfabetização. Esses censos mantiveram o conceito de pessoa alfabetizada e ampliaram o entendimento sobre analfabeto, ao considerar "Aquelas que aprenderam a ler e escrever, mas esqueceram as que apenas assinassem o próprio nome" (IBGE 1983: xxix). Esses quatro censos diferenciaram-se dos anteriores na forma de apresentação dos seus resultados. Quanto à alfabetização foram reduzidos para 10 os grupos de idades em 1960; ampliados para 14 grupos em 1970 e 1980; e para 16 grupos em 1991. A partir de 1991 a pesquisa sobre alfabetização desconsiderou a situação de domicílio e passou a contemplar o sexo e a cor ou raça, segundo os grupos de idade. Constatam-se, na divulgação dos três 
últimos censos, informações adicionais sobre a frequência e os anos de estudos das pessoas de 5 anos ou mais, inclusive com indicação sobre frequência e conclusão de curso de alfabetização de adultos, que aparece, pela primeira vez como um grau de ensino elementar no censo de 1970. Nesses censos o país apresentou uma taxa de analfabetismo de 25,5\% em 1980 e 20,1\% em 1991 para as pessoas de 15 anos ou mais de idade.

Nas Notas Metodológicas da publicação dos Resultados da Amostra do censo de 2000, enfatiza-se o contexto internacional relativo à pesquisa. Neste aspecto, quanto ao planejamento tem-se que "foram consideradas as recomendações de organismos internacionais e a experiência dos Órgãos Nacionais de Estatística de diversos países" (IBGE 2003: 16). Enfatiza-se que o Brasil, através do IBGE, participa de seminários e fóruns internacionais de debates sobre censos e que seus especialistas realizaram visitas técnicas aos principais órgãos de estatística do mundo, bem como teve uma participação efetiva na discussão dos conceitos e definições incluídos nas Recomendações Internacionais, elaboradas pelas Nações Unidas. Desde 1997, participa do Projeto do Censo Comum do MERCOSUL, em conjunto com os órgãos de estatística dos demais países do bloco continental, constituído por Argentina, Brasil, Paraguai e Uruguai, aos quais se somaram Chile e Bolívia.

Nesse censo foram investigados a alfabetização, a rede de ensino e o nível de ensino frequentado ou o mais elevado que foi atingido pela pessoa. $\mathrm{O}$ entendimento e a forma de apuração quanto à alfabetização mantiveramse idênticos aos censos de 1980 e 1991. Mais uma vez os grupos de idades foram reduzidos, passando a serem apresentados 14 grupos. Em 2000 o país possuía 24,09 milhões de pessoas analfabetas com 5 anos ou mais de idade e apresentava uma taxa de analfabetismo das pessoas de 15 anos ou mais de idade de $13,6 \%$, ou seja, 6,5\% menor que a de 1991 .

Com relação à alfabetização, o censo de 2010, conforme as notas técnicas sobre as Características da População e dos Domicílios - Resultados do Universo (IBGE 2011) apresenta o mesmo conceito do censo anterior para a pessoa alfabetizada, mas ampliou o de pessoa analfabeta, considerando como "a pessoa que aprendeu a ler e escrever, mas que esqueceu devido a ter passado por um processo de alfabetização que não se consolidou e que apenas assinava o próprio nome". $\mathrm{Na}$ análise dos resultados desse censo evidencia-se que se considera alfabetização como "o primeiro passo para o acesso à informação escrita e a níveis de educação mais elevados" (IBGE 2011: 84). Os resultados indicaram que o país apresentava 14,6 milhões de pessoas de 10 anos ou mais de idade que não sabiam sequer ler e escrever um bilhete simples, o que representava uma taxa de analfabetismo de $9 \%$, porém esta taxa para as pessoas de 15 anos ou mais de idade ainda foi um pouco maior, $9,6 \%$. 


\section{As Mudanças do Conceito de Alfabetização}

Ao buscar reconstruir de forma breve a trajetória conceitual da alfabetização e do analfabetismo, Ferraro (2002) afirma que a assinatura do próprio nome tem sido um indicativo de alfabetização utilizado historicamente, enquanto que a assinatura em forma de cruz, o de analfabetismo. E complementa que tanto esses indicativos quanto a definição censitária de saber ler e escrever estiveram em vigor desde os primeiros censos demográficos no Ocidente até as primeiras décadas do século XX.

Cabe inicialmente refletir que as pesquisas censitárias baseiam-se na declaração do recenseado, que não é comprovada no sentido de exigir-se que leia e escreva um bilhete, ou até mesmo assine seu nome. Pelo próprio preconceito que o significado de ser analfabeto carrega na sociedade, o simples fato de alguém ser levado a responder sim ou não sobre saber ler e escrever ou assinar seu nome não garante que os resultados censitários apontem a real situação da alfabetização no país. Mas não sendo este o objetivo da nossa reflexão, podendo vir a ser objeto de estudos posteriores, cabe refletir sobre as mudanças que o conceito de alfabetização vem sofrendo nos censos e no âmbito epistemológico.

Conforme Ferraro (2002), a alteração do conceito de alfabetização no censo de 1950 foi influenciada pela Organização das Nações Unidas para Educação, Ciência e a Cultura (UNESCO), não só no Brasil, mas em outros países, a exemplo da Argentina. Ele afirma que até mesmo o IBGE confundese na explicação quanto aos critérios sobre alfabetização, ora afirmando que não houve mudanças em relação ao censo de 1940 e ora afirmando que foram utilizados critérios mais rigorosos.

Evidencia-se a partir de Carvalho et al (in IBGE 1994) no início de 1990 a existência de duas realidades (uma de ordem conceitual e outra de ordem empírica) que recomendavam a criação de indicadores mais significativos sobre (an) alfabetização para além da tradicional delimitação que aceitava apenas uma declaração que alguém "não sabia" ou "sabia ler e escrever". Suas análises esclarecem de forma satisfatória os diversos constructos que passaram a existir sobre o continuum de analfabetismo-alfabetização.

Ainda segundo esses autores, conceitualmente, desde 1960, a UNESCO e seus países membros, entre eles o Brasil, estabeleceram o critério da funcionalidade de alfabetização no que se refere ao domínio de habilidades suficientemente necessárias para inserção do cidadão no desenvolvimento de sua comunidade e do país. Empiricamente dois aspectos contribuíram para a operacionalização dos indicadores de analfabetismo e alfabetização utilizados no Brasil: o programa do Movimento Brasileiro de Alfabetização - MOBRAL, criado em 1967, que visava à alfabetização funcional de jovens e adultos; e a 
Constituição Federal de 1988, com a exigência de uma escolaridade completa de $1^{\circ}$ grau (internacionalmente considerado o patamar mínimo de alfabetização funcional), como direito público subjetivo, mesmo para aqueles que não tiveram acesso à escola na infância e (pré) adolescência.

Claramente percebe-se que os critérios utilizados pelo Brasil não são próprios, haja vista a confusão nos entendimentos: as afirmações de Ferraro (2002), de Carvalho et al (in IBGE: 1994) e as convenções internacionais mencionadas nas pesquisas pelo IBGE. Por serem critérios determinados por organismos externos entende-se que a preocupação é, acima de tudo, com a divulgação de indicadores a serem apresentados externamente, não se configurando como uma preocupação prioritária com os problemas internos do país. Neste sentido, a escolha é por utilizar conceitos e parâmetros que são orientados internacionalmente, por organismos que o Brasil optou por seguir.

Na perspectiva de Carvalho et al (in IBGE 1994), os indicadores do analfabetismo e da alfabetização, com o propósito de balizar diversos níveis ao longo de um continuum, utilizam vários constructos pelos quais se definem patamares de habilidades de lecto-escritura e cálculos aritméticos, a saber:

Analfabetismo: corresponde ao reconhecimento do informante em não saber ler e escrever.

Semi-analfabetismo: fica caracterizado quando os informantes da pesquisa dizem saber ler e escrever, mas não completam sequer uma única série escolar.

Alfabetização-básica: está associada ao "ciclo básico de alfabetização" hoje implementado por diversas administrações estaduais e municipais, o qual integraliza o processo de alfabetização, ao longo de, no mínimo, duas séries escolares.

Alfabetização complementar: define-se poralguma complementação do ciclo básico de alfabetização, mas que se tenha atingido o nível funcional; corresponde à $3^{\mathrm{a}}$ série.

Alfabetização funcional: corresponde ao domínio de conteúdos de leitura, escrita, aritmética e ciências, proporcionado pelo antigo ensino primário ou por uma escolaridade de $4^{\mathrm{a}}$ série completa, anteriormente prescrito pela UNESCO e, em princípio buscado como meta por programas de alfabetização de adultos, como o MOBRAL.

Alfabetização pós-funcional: corresponde ao presumível estágio de domínios de habilidades e conhecimentos associados às séries finais ( $5^{\mathrm{a}}$ as $7^{\mathrm{a}}$ séries) do primeiro grau de ensino.

Alfabetização completa: corresponde ao domínio dos conteúdos curriculares do $1^{\circ}$ grau completo, como patamar mínimo já fixados em países desenvolvidos e como meta legalmente estabelecida pela 
Constituição de 1988 como direito público subjetivo, não apenas para população em idade escolar, mas até mesmo para o demais cidadãos [...].

Escolaridade pós-1 $1^{\circ}$ grau de ensino: corresponde a um estágio de habilidades de leitura, escrita, cálculos e conhecimentos científicos mais compatível com o desenvolvimento técnico-científico (Carvalho; Kapel; Alves in IBGE 1994: 284-285).

Com base no relatório mais recente da ONU, Atchoarena e Gasperini (2003: 20-21) explicitam que o alfabetizado é aquele que lê e escreve, "com discernimento, uma frase curta e simples sobre sua vida cotidiana"; o estado de alfabetização funcional é então definido como o daquele sujeito que detém conhecimentos teórico-práticos fundamentais que lhe permitem empreender atividades em que a alfabetização é necessária para sua atuação eficaz e contínua para si, para seu grupo e comunidade, com um domínio suficiente da leitura, escrita e cálculo.

Em publicação mais recente, Henriques (2006: 20-21) ao elaborar um histórico sobre as iniciativas públicas federais na alfabetização de jovens e adultos no Brasil, também menciona a evolução do termo alfabetização, afirmando:

Até por volta da década de 1950 , era considerada alfabetizada a pessoa que tivesse a habilidade de ler e escrever um texto simples e que dominasse o código alfabético. Essa concepção foi se tornando mais complexa, passando a incorporar o domínio da língua falada e escrita em um contexto social, assim como a dimensão cultural, política e de conquista dos direitos de cidadania. Alguns especialistas brasileiros utilizam a palavra letramento (do inglês literacy) para nomear esse conceito. A partir da década de 1970, a Unesco passou a utilizar o termo analfabetismo funcional, que corresponderia ao fenômeno no qual a pessoa sabe ler e escrever, mas não alcança o domínio social da leitura e da escrita, alertando para a necessidade de se estender a todos o acesso à escolarização básica, a fim de se garantir tal domínio. Desde então, vêm sendo adotados diversos acordos e planos internacionais que aprofundaram esse entendimento relacionando-o à diversidade e à educação ao longo de toda a vida (Henriques 2006: 20-21).

Conforme Soares (2014), até a década de 1990, existia um consenso sobre os conceitos de analfabeto (o que não sabe ler e escrever), analfabetismo (o estado ou condição de quem não sabe ler e escrever) e alfabetização (o processo de ensinar a ler e a escrever); porém, progressivamente, foi-se revelando uma tendência de qualificar e precisar esses conceitos, ampliando-se seu significado. A autora complementa afirmando que nesse período começaram a surgir os ciclos básicos de alfabetização 
[...] proposta que se consolidou com a posterior organização do ensino fundamental em ciclos, a ampliação do tempo para a alfabetização significando que a esta cabe não apenas ensinar a ler e a escrever, mas também desenvolver habilidades de uso social da leitura e da escrita e gosto pelo convívio com material escrito. Ao mesmo tempo, e como consequência, vai-se modificando a metodologia da alfabetização, passando a defender-se que essa se dê não por meio das tradicionais cartilhas, voltadas exclusivamente para a mecânica da leitura e da escrita, mas pelo convívio do alfabetizando com o material escrito que circula na sociedade, em diferentes gêneros e diferentes portadores (Soares 2014).

Em conformidade com esta tendência mencionada pela autora, a UNESCO (2009: 8), afirma que "as formas de avaliação dos graus de alfabetização estão cada vez mais focadas no que as pessoas realmente conseguem fazer em termos de leitura e escrita, usando testes diretos". São métodos que ainda conforme a UNESCO (2009: 8), "afastam-se da dicotomia alfabetização/analfabetismo e se aproximam de um continuum de graus de alfabetização, assim permitindo um foco melhor para os programas".

Uma tentativa de averiguar os níveis de habilidades, citados por Carvalho et al (in IBGE 1994) nas pesquisas censitárias, pode ser considerada a inclusão em 1960 da investigação quanto aos anos de estudo da população (Ferraro 2002) e a comparação realizada dos níveis de letramento com as informações censitárias de anos de estudo da população). Consideramos ser insuficiente o critério de determinar o nível de alfabetização da população apenas pela análise da quantidade de anos de estudo, conforme demonstram os estudos de Soares (2014) e Carvalho et al (in IBGE 1994) e a realidade do analfabetismo funcional.

É relevante enfatizar que, além do Censo Demográfico, os indicadores de analfabetismo e grau de escolaridade da população passaram a ser investigados, com periodicidade anual, nos levantamentos da PNAD, também realizados pelo IBGE, e que, especificamente a alfabetização, tem sido objeto das pesquisas realizadas por instituições não governamentais, como a ONG Ação Criança e pelo Instituto Paulo Montenegro, parceiros na criação e implementação do Indicador de Alfabetismo Funcional - INAF.

Nos resultados apresentados pela PNAD divulga-se a taxa de analfabetismo funcional, representada pela proporção de pessoas de 15 anos ou mais de idade com menos de 4 anos de estudos completos em relação ao total de pessoas desta mesma faixa etária. A evolução dessa taxa nas últimas décadas, conforme o Gráfico 1 aponta para percentuais bem mais elevados do que as taxas de alfabetização apresentadas nos censos. Em 2012, por exemplo, a taxa de analfabetismo funcional, $18,3 \%$, foi quase o dobro da taxa de analfabetismo das pessoas de 15 anos ou mais apurada pelo censo do mesmo ano, que foi $9,6 \%$. 


\section{Gráfico 1 - Taxas \\ de Analfabetismo Funcional e \\ Taxa de Analfabetismo Absoluto \\ Brasil ( 2001-2012)}

30

25

20

15

10

5

0
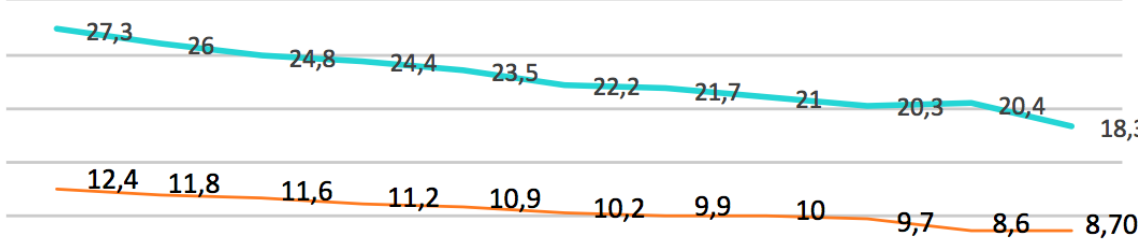

$\begin{array}{lllllllllll}2001 & 2002 & 2003 & 2004 & 2005 & 2006 & 2007 & 2008 & 2009 & 2011 & 2012\end{array}$

Fonte: IBGE, 2014.

Diante do exposto questiona-se: por que manter na pesquisa do Censo Demográfico sobre alfabetização, um conceito limitado até mesmo pelo que reconhecem os organismos orientadores das convenções internacionais, a exemplo da UNESCO, se este resultado não reflete a real situação do nível de (an) alfabetismo do país? Por que segmentar as pesquisas sobre educação que apenas confundem as análises e impedem que as propostas para melhoria da qualidade educacional do país sejam baseadas em dados mais consistentes, integrados e aproximados da realidade?

Machado (2015), ao estudar as políticas educacionais para a educação de jovens e adultos no Brasil, particularmente o Programa Brasil Alfabetizado (PBA), o caso do Sergipe Alfabetizado (SEALF), quanto ao processo de execução e aos seus resultados, à luz de uma abordagem sociocrítica das políticas públicas, revela que, paradoxalmente, o governo brasileiro investe hoje alto montante de recursos em um programa não formal de alfabetização, com seus limites, em termos de continuidade e reconhecimento social dos estudos desenvolvidos, inclusive, trabalhando com alfabetizadores sem formação para o magistério. 


\section{Considerações Finais}

O estudo procurou elucidar que, desde as primeiras pesquisas censitárias no Brasil, existiu a tendência a equívocos na forma de investigar os dados sobre a educação, que no fundo já estava associada a uma posição políticoideológica. Foi assim no censo de 1920, com prevalência da subjetividade e em 1940 quando se atribuiu determinada resposta a uma situação de abstenção, arbitrariamente.

A análise desenvolvida confirmou a hipótese de que o conceito de alfabetização nos levantamentos censitários do Brasil, embora tenha se alterado ao longo das pesquisas, a exemplo dos anos de 1950, 1980 e 2000, não incorporaram a ampliação do seu significado no que diz respeito a sua evolução epistemológica e metodológica. Assim, as informações decorrentes dos censos acabaram subsidiando de forma fragmentada e insuficiente a formulação de políticas públicas nesta área, impedindo, em especial a superação do analfabetismo que, por essa via, tem sido tratado mediante programas descolados da educação básica, desconsiderando a continuidade requerida pelo processo de alfabetização que se complementa por toda a educação formal. Desse modo não se avança na construção de propostas para superação do quadro do analfabetismo que perdura ao longo da nossa história.

É questionável que o país mantenha esse nível de investigação e informações que mascaram a realidade e induzem à aplicação de recursos priorizando pseudo-indicadores que interessam mais a organismos internacionais, atendem a interesses externos, do que aos próprios interesses da nação. Na verdade, trata-se mais do que do poder das estatísticas! É uma questão política que se vincula a uma ideologia. No contexto do Estado capitalista liberal (neoliberal ou pós-neoliberal) é evidente a ambivalência desse Estado em relação à educação, vista, ao mesmo tempo, como necessária e imprescindível ao desenvolvimento socioeconômico (desde a Educação Básica) e ameaçadora da ordem estabelecida.

As políticas educacionais pós 1990 no Brasil atendem a uma ordem global das diretrizes de organismos supranacionais, que estão voltados para manutenção do capitalismo, no qual os países pobres ou em desenvolvimento precisam do financiamento dos países desenvolvidos para atingirem uma favorável mobilidade econômica, e não atendem de fato aos problemas que a realidade nacional impõe.

Ferraro (2009) fala do analfabetismo no Brasil como uma história inacabada... De fato, a história não acabou. Perguntamo-nos até quando assim permaneceremos, já que somos sujeitos desta história! É uma questão também de compromisso e vontade política a partir da sociedade civil organizada e da formação dos intelectuais, de modo a que possamos fazer frente às novas 
formas de governação que estão sendo propostas, mantidas características como a descentralização das ações, as parcerias público-privado, a subserviência às recomendações de organismos internacionais e a flexibilização das formas de trabalho e formação dos alfabetizadores. Necessitamos da implantação de políticas públicas que potencializem e fortaleçam a intersetorialidade, o que requer o protagonismo de cada cidadão do país.

Desta forma, o indicador estudado tem reforçado a tendência ao fortalecimento da concepção de educação neoliberal que valoriza o individualismo e a autogestão do sujeito, na sua formação ao longo da vida, em detrimento da responsabilidade do Estado em relação ao seu dever para com a garantia da formação inicial e continuada formal dos trabalhadores. Mas a consciência da população e a organização da sociedade civil também são capazes de galgar novos horizontes na direção de modos de produção de existência humana, para o que a literacia é fundamental. 


\section{REFERÊNCIAS}

Almeida, Paulo Roberto de (2001). Formação da diplomacia econômica no Brasil: as relações econômicas internacionais do Império. São Paulo: Cromosete.

Atchoarena, David (UNESCO); Gasperini, Lavinia (FAO) (Coords.). (2003). Education for rural development: towards new policy responses. Roma, Itália; Paris, França: UNESCO/FAO. http://www.unesco.org/education/ efa/know_sharing/flagship_iniciatives/towards_new_policy.pdf

Bezerra, Ada Augusta Celestino; Chaves, Natalina Bissaro Siqueira (2013). "O rural como objeto de estudo na educação: campo de abrangência e significado atual”. In: BEZERRA, Ada Augusta Celestino e NASCIMENTO, Marilene Batista da Cruz. Educação e formação de professores: questões contemporâneas. Ceará: UFC.

Carvalho, José Carmelo Braz; KAPPEL, Maria Dolores Bombardeli; ALVES, Maria Isabel Coelho (1994). "Evolução das condições educacionais". In: IBGE. Indicadores sociais: uma análise da década de 1980. Rio de Janeiro: IBGE.

Cury, Claudia Engler (2006). "Métodos de ensino e formas de controle sobre o cotidiano escolar na instrução pública da Parahyba do Norte (183518640)". In: SCOCUGLIA, Afonso Celso e MACHADO, Charliton José dos Santos (orgs). Pesquisa e historiografia da educação brasileira. Campinas: Autores Associados.

Faria Filho, Luciano Mendes (2000). "Instrução elementar no século XIX”. In: LOPES, Eliane Marta Teixeira; FARIA Filho, Luciano Mendes e VEIGA, Cynthia Greive. 500 anos de educação no Brasil. Belo Horizonte, Autêntica.

Ferraro, Alceu Ravanello (2002). Analfabetismo e níveis de letramento no Brasil: o que dizem os censos? Educação e Sociedade. Campinas, vol. 23, n. 81, p. 21-47, dez 2002.

Ferraro, Alceu Ravanello (2009). História inacabada do analfabetismo no Brasil. São Paulo: Cortez.

Freire, Ana Maria Araújo (2001). Analfabetismo no Brasil: da ideologia da interdição do corpo à ideologia nacionalista, ou de como deixar sem ler e escrever desde as Catarinas (Paraguaçu), Filipas, Madalenas, Anas, Genebras, Apolonias e Gracias até os Severinos. 3. ed. São Paulo: INEP-Cortez.

Henriques, Ricardo. (2006) "Alfabetização e inclusão social: contexto e desafios do programa

Brasil alfabetizado". In: HENRIQUES, Ricardo; BARROS, Ricardo Paes de; AZEVEDO, João Pedro (coord). Brasil alfabetizado : caminhos da avaliação. Brasília: Secretaria de Educação Continuada, Alfabetização e Diversidade. (Coleção Educação para Todos, Série Avaliação ; n. 1, v. 18). 
IBGE (1956). Censo demográfico de 1950. Disponível em: http:// biblioteca.IBGE.gov.br/visualizacao/periodicos/67/cd_1950_v1_br.pdf>.

IBGE (1983). Censo demográfico: dados gerais, migração, instrução, fecundidade, mortalidade. Rio de Janeiro: IBGE.

IBGE (2003). Censo demográfico de 2000: características da população e dos domicílios - resultados do universo. Rio de Janeiro: IBGE.

IBGE (2011). Censo demográfico de 2010: características da população e dos domicílios - resultados do universo. Rio de Janeiro: IBGE.

IBGE (2013). Censo demográfico de 1920. Disponível em: <http:// biblioteca.IBGE.gov.br/visualizacao/periodicos/68/cd_119960_v1_br.pdf $>$.

IBGE (2014). Séries históricas e estatísticas. Taxa de analfabetismo funcional. Disponível em: <http://seriesestatisticas.IBGE.gov.br/series. aspx? no $=1 \&$ op $=1 \&$ vcodigo $=$ PD384\& $\mathrm{t}=$ taxa-analfabetismo-funcional $>$.

Machado, Márcia Alves de Carvalho. Políticas educacionais no Brasil na área de educação de jovens e adultos: o caso do Programa Brasil Alfabetizado em Sergipe. Aracaju: UNIT (Dissertação de Mestrado).

Oliveira, Luiz Antonio Pinto de; Simões, Celso Cardoso da Silva. "O IBGE e as pesquisas populacionais". In: Revista Brasileira Estudos de Populaçao. São Paulo, v. 22, n. 2, p. 291-302, Dec. 2005. Disponível em:

$<$ http://www.scielo.br/scielo. php?script=sci_arttext\&pid=S0102-

30982005000200007\&lng=en\&nrm=iso $>$.

Paiva, Vanilda (1990). "Um século de educação republicana". In: Proposições. Campinas: UNICAMP, vol.1(2), julho/1990, p.7-18.

Soares, Magda Becker (2014). "Alfabetização: acesso ao código ou acesso à leitura?” In: Site Leia Brasil. Disponível em:

http://www.leiabrasil.org.br/old/leiaecomente/c\%C3\%B3digo_leitura. htm.

UNESCO (2009). O desafio da alfabetização global. Brasília: UNESCO. 